\title{
Control and data acquisition system to study dielectric breakdown in low-pressure DC plasma reactor with parallels electrodes
}

\section{Desenvolvimento de um sistema de controle e aquisição de dados para estudo de ruptura dielétrica em reatores de plasma DC de baixa pressão com eletrodos paralelos}

Bernardo Vieira Magaldi1,2,* (D), Rodrigo Savio Pessoa1,2, Mateus Pereira Cesare² (D), Afonso André Ribeiro² (D), Cristiane Aparecida Martins ${ }^{3}$ (D), Argemiro Soares da Silva Sobrinho 1,2 (D)

1. Departamento de Ciência e Tecnologia Aeroespacial - Instituto Tecnológico de Aeronáutica - Laboratório de Plasmas e Processos - São José dos Campos (SP), Brazil.

2. Departamento de Ciência e Tecnologia Aeroespacial - Instituto Tecnológico de Aeronáutica - Departamento de Engenharia Mecânica Aeronáutica - São José dos Campos (SP), Brazil.

3. Departamento de Ciência e Tecnologia Aeroespacial - Instituto Tecnológico de Aeronáutica - Laboratório de Combustão, Propulsão e Energia - São José dos Campos (SP), Brazil.

Correspondence author: magaldi.ita@gmail.com

Section Editor: Nome Sobrenome

Received: 9 Dec 2021 Approved: 12 Dec 2021

\begin{abstract}
This work aimed to present the theory of dielectric breakdown of a glow discharge through the automation of gas injection (mass flow) systems with pressure control (pressure gauge) and voltage source with voltage control, in the reactor for the acquisition of rupture parameters for low-pressure glow discharges. Through the analysis of Paschen's curves for the configuration with argon gases and atmospheric air, it was observed that the rupture potential for argon gas is lower than for atmospheric air, although the ionization potential of atmospheric air is lower about argon.
\end{abstract}

KEYWORDS: Plasma reactor, Cold plasma, Glow discharge, LabVIEW®, Data acquisition.

\begin{abstract}
RESUMO
Este trabalho teve como objetivo apresentar a teoria da ruptura dielétrica em uma descarga luminosa através de um sistema automatizado de injeção de gás (mass flow) com controle de pressão (pressure gauge) e fonte de tensão com controle de tensão, no reator para aquisição de parâmetros de ruptura em baixa pressão de forma padronizada pelo sistema de controle desenvolvido. Ao analisar as curvas de Paschen das configurações de argônio e ar atmosférico, observou-se que o potencial de ruptura do argônio é menor que o do ar atmosférico, embora o potencial de ionização do ar atmosférico seja menor em relação ao argônio.
\end{abstract}

PALAVRAS-CHAVE: reator de plasma, plasma frio, descarga luminosa, LabVIEW®, aquisição de dados.

\section{INTRODUCTION}

The electric discharge on electrodes presenting a potential difference between them occurs at a well-defined combination of gas pressure, the distance between these two surfaces and the submitted voltage, as described by Paschen's law'. Understanding when the discharge occurs under the conditions of the application is essential for designing and adjusting devices for a reactor or instrument, as well as for understanding the electrical discharge processes that occur in the process. The Paschen's curves measured for atmospheric air and argon will be presented 
and the results compared with the voltages found in the literature 2 . Possible implications for the treatment of the data obtained on the theory of dielectric rupture of gas, given ahead, will be also discussed.

\section{Dielectric breakdown of a gas}

The process of electric rupture of gas is characterized by an exponential increase of the discharge current when a certain voltage between the electrodes is reached, the so-called rupture voltage' ${ }^{1}$. This rupture process is basically in the region of the V-I curve, known as the dark discharge region or Townsend's regime (Fig. 1), and it is described, in the case of parallel low-pressure electrodes, by the Townsend's model and Paschen's theory ${ }^{2,3}$.

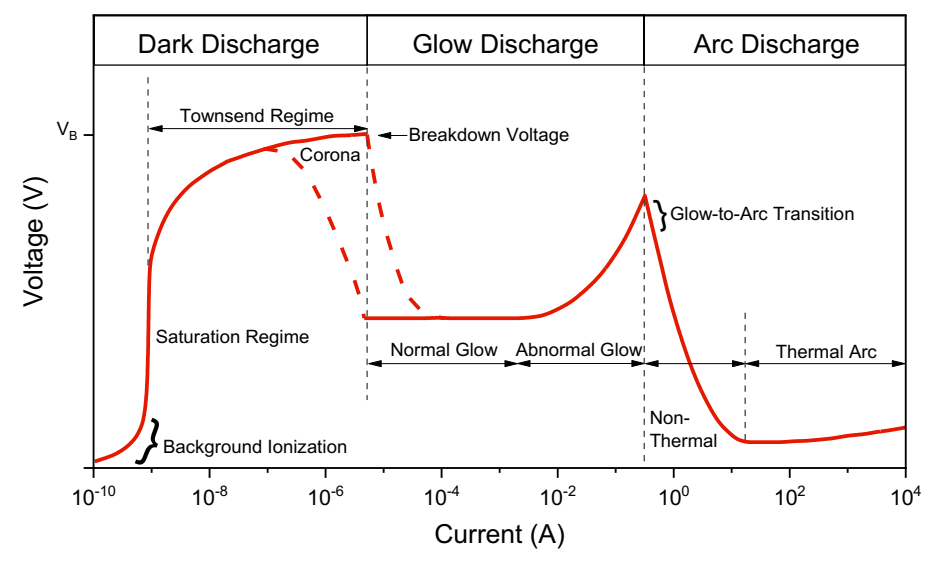

Source: Rodrigo Pessoa's thesis ${ }^{3}$.

Figure 1: V-I curve for low-pressure gas discharge.

Townsend's model allows a good understanding of the experiment by assuming that in each collision the electron transfers all its energy to the atom, ionizing it. By ionizing the gas, an amount $e^{a x}$ ( $a=$ number of ionizations; $\mathrm{x}=$ distance between electrodes) of electrons will be generated.

Ionization efficiency can be also explained by the Townsend's model, which is the number of ionizations per electric field unit (Eq. 1):

$$
\eta=\frac{\alpha}{E}=\frac{\alpha / p}{E / p}
$$

or

$$
\eta=\frac{A}{E / p} e^{\frac{B}{E / p}}
$$

In which: $p=$ pressure.

The parameters A and B given in the Eqs. 1 and 2 are obtained experimentally. The electrons produced in the middle of the discharge are not enough to maintain it, so we must consider another secondary electron emission process, which leads to Paschen's law4.

Paschen's law describes the behavior of the breakdown voltage as a function of the product pd (pressure $\times$ distance between the electrodes). Thus, the breaking process is dependent on both the E/p ratio and the product pd.

The source of electrons, other than those generated by the discharge, is the emission of secondary electrons from the cathode due to the impact of positive ions. The number of electrons that reach the anode tends to infinity, and the discharge is self-sustaining without the need for external radiation to maintain it.

\section{The physical meaning of $\mathrm{E} / \mathrm{p}$}

Plasma collisions come from movements of ions and electrons. When an E field is applied, ions are accelerated in the same direction as $\mathrm{E}$, while electrons move in the opposite direction. Depending on the velocity of electron collision with the atom, the collision ionization effect may be possible. 
The average electron energy becomes dependent on $\mathrm{E}$ and inversely dependent on density $\mathrm{N}$ (or pressure p, since $p=N k T)^{2}$ (Eq. 3).

$$
\text { Energy }=\frac{E}{p}
$$

Depending on the E/p ratio, a high current growth rate may occur, which culminates in the gas rupture being a self-sustaining process. Thus, the E/p ratio is understood as the average energy acquired between electron collisions and determines whether or not a gas rupture can occur.

\section{Townsend's model}

Townsend's model describes the abrupt increase in discharge current during the rupture process. The model starts from a free electron that acquires from the electric field energy greater than the ionization potential of the atoms (or molecules) that make up the gas, in which in each collision the electron loses all its energy and the probability of ionization in each collision is equal to 1.

The number of electrons ( $d n$ ) created at a distance $d x$ between the electrodes is proportional to the initial number of electrons $n$ and the distance traveled $d x(\text { Eq. } 4)^{2}$.

$$
d n=\alpha n d x
$$

In which the proportionality constant a is the number of ionizations per unit of distance. Therefore, by Eq. 4 , it results in Eq. 5.

$$
n=n_{0} e^{\alpha x}
$$

When the discharge voltage reaches the so-called rupture voltage, each electron in the discharge with enough energy to ionize a gas atom generates $e^{a x}$ electrons, that is, the current increases exponentially between the electrodes from the moment the electric field provides enough energy for the discharge electrons. This process is called avalanche and is represented by Fig. 2.

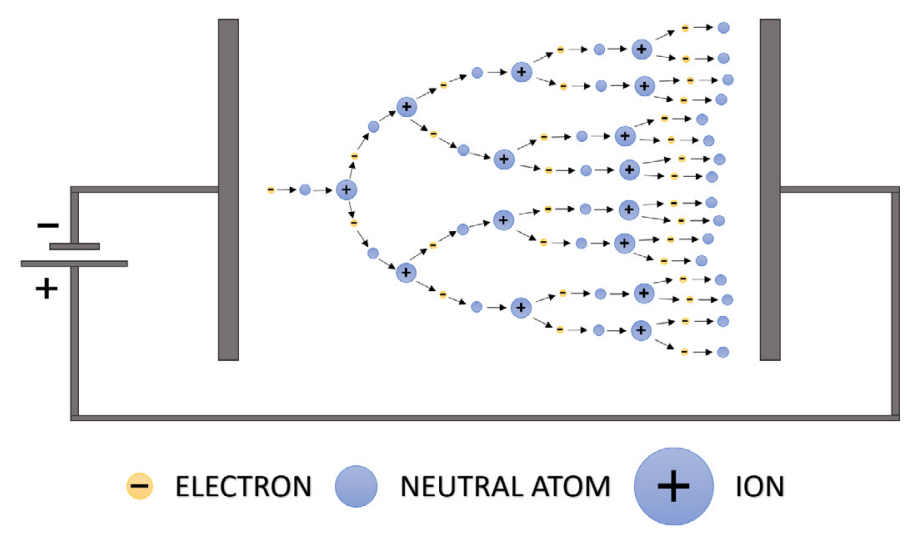

Figure 2: Avalanche process during rupture.

The conditions for atoms and electrons to collide to obtain energies above the ionization potential of the gas particles are met if (Eq. 6):

$$
e E \lambda_{i} \geq e V_{i}
$$

In which: e: the fundamental charge; $E$ : the electric field; $\lambda_{i}$ : the free mean ionization path; $V_{i}$ : is the ionization potential, i.e. (Eq. 7): 


$$
\lambda_{i}=\frac{V_{i}}{E}
$$

Being $1 / \lambda$ the total number of collisions per distance unit, it results in Eq. 8:

$$
\alpha=\frac{1}{\lambda} e^{-\frac{\lambda_{i}}{\lambda}}
$$

Knowing that $1 / \lambda$ is proportional to pressure and using Eq. 4, as shown in Eq. 9:

$$
\alpha=A p e^{-\frac{A p V_{1}}{E}}
$$

In which: $A=$ a temperature-dependent constant.

Doing $B=A V_{1}$, we can write in the usual way (Eq. 10):

$$
\frac{\alpha}{p}=A e^{-\frac{B}{E / p}}
$$

Using Eq. 10, it follows that (Eq. 11):

$$
\eta=\frac{A}{E / p} e^{-\frac{B}{E / p}}
$$

The Townsend's model described previously explains the multiplication of electrons in the rupture process and provides data on ionization efficiency ${ }^{2,4}$. However, parameters A and B, as well as the breakdown voltage, can only be determined experimentally. A detailed analysis shows that the main process is the emission of secondary electrons, which leads to Paschen's law.

\section{Paschen's law}

The Paschen's law describes the behavior of breakdown voltage as function of the product pd. The product pd is related to the number of collisions that electrons make on their trajectory from the cathode to the anode since the pressure is inversely proportional to the mean free path. Substituting the expression for a (Eq. 10) in Eq. 5 and making $x=d$, we have Eq. 12:

$$
n=n_{0} \exp \left[A p d e^{-\frac{B}{E / p}}\right]
$$

That is, the rupture process is dependent on both the E/p ratio and the product pd. Since $y$ is the emission coefficient of secondary electrons, it has (Eq. 13):

$$
n=n_{0} \frac{e^{\alpha d}}{1-\gamma\left(e^{\alpha d}-1\right)}
$$

Equation 13 becomes indeterminate and the discharge is self-sustaining, that is, there is no need for external radiation to maintain the discharge ${ }^{2,3}$. Paschen's law relates the breakdown voltage to the product pd using Eq. 10 and replacing $E$ with $\mathrm{V}^{\mathrm{b}} / \mathrm{d}$, in which $\mathrm{V}_{\mathrm{b}}$ is the breakdown voltage, as shown in Eq. 14:

$$
V_{b}=\frac{B p d}{\ln \left[\frac{A p d}{\ln \left(1+\frac{1}{\gamma}\right)}\right]}
$$

The ionization potential and the minimum $p \cdot d$ product are related to B as follows (Eq. 15): 


$$
B=\frac{V_{i}}{p d_{\min }}
$$

The Paschen's curve has a minimum, that is the minimum voltage that the discharge can operate. Deriving the Eq. 14 and equating to 0 has that (Eqs. 16 and 17):

$$
\begin{gathered}
p d_{\text {min }}=\frac{e}{A} \ln (1+1 / \gamma) \\
\left(V_{b}\right)_{\text {min }}=e \frac{B}{A} \ln (1+1 / \gamma)
\end{gathered}
$$

The secondary electron emission coefficient $\mathrm{y}$ is also a function of $\mathrm{E} / \mathrm{p}^{3}$. The break criterion can be written as Eq. 18:

$$
\gamma=\frac{1}{e^{\eta V}-1}
$$

Since ionization efficiency $\eta$ is a function of $E / p$, so $y$ is also a function of $E / p$. Although the emission of secondary electrons is the main one, in the above equations $y$ also encompasses photoionization and other processes.

\section{METHODOLOGY}

A methodology designed for the LabVIEW® software interface was planned to allow the control and reading of fundamental data in a simplified manner, in which the direct (voltage and pressure) and indirect (gas type, electrode distance, reactor geometry, etc.) controllable parameters would be chosen for each desired study type, as shown in the schematic diagram of Fig. 3, and a sketch of the circuit in Fig. 4.

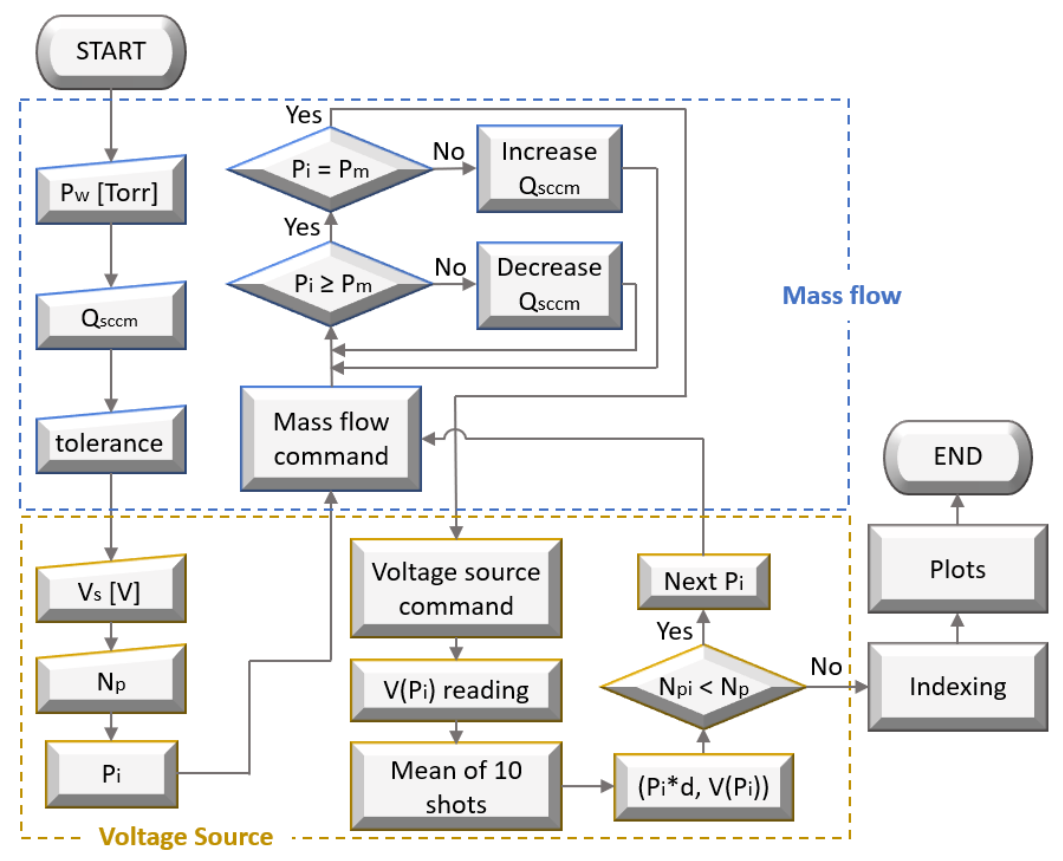

Figure 3: Methodological diagram of the system.

A schematic drawing of the system, as well as an overview of the experimental apparatus, is shown in Fig. 4. 


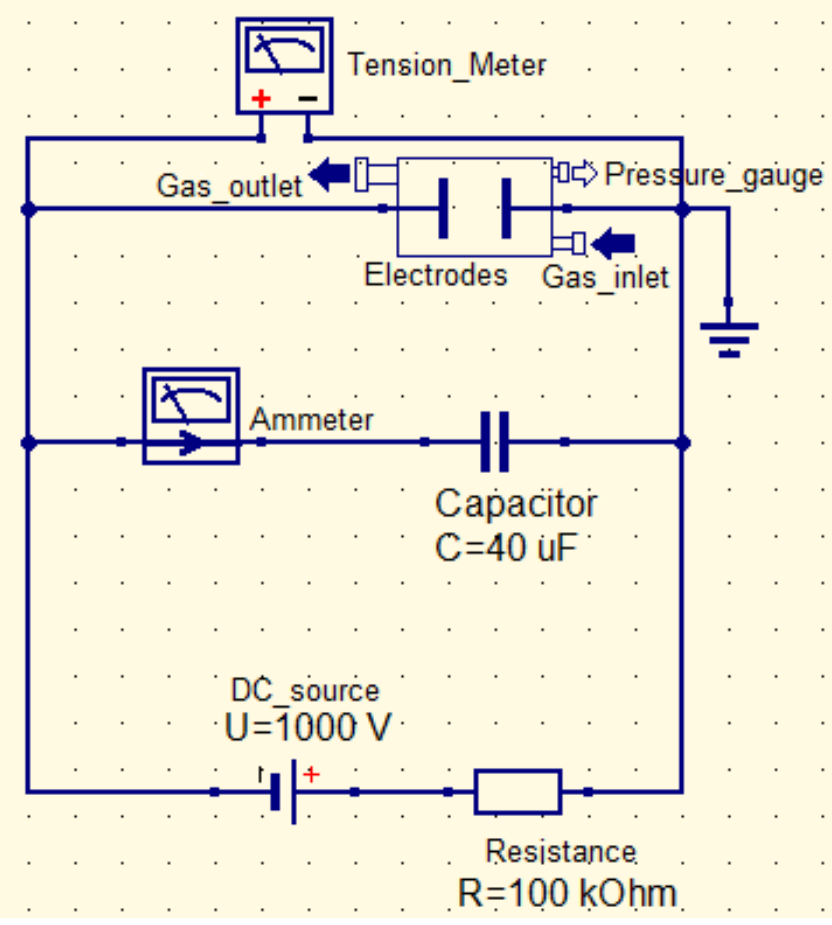

Figure 4: Schematic drawing of the experimental system.

Given the pressure points to be inserted into the interface and the acceptable tolerance, the software will indicate whether to increase or decrease the gas flow in the reactor, as shown in Fig. 5.

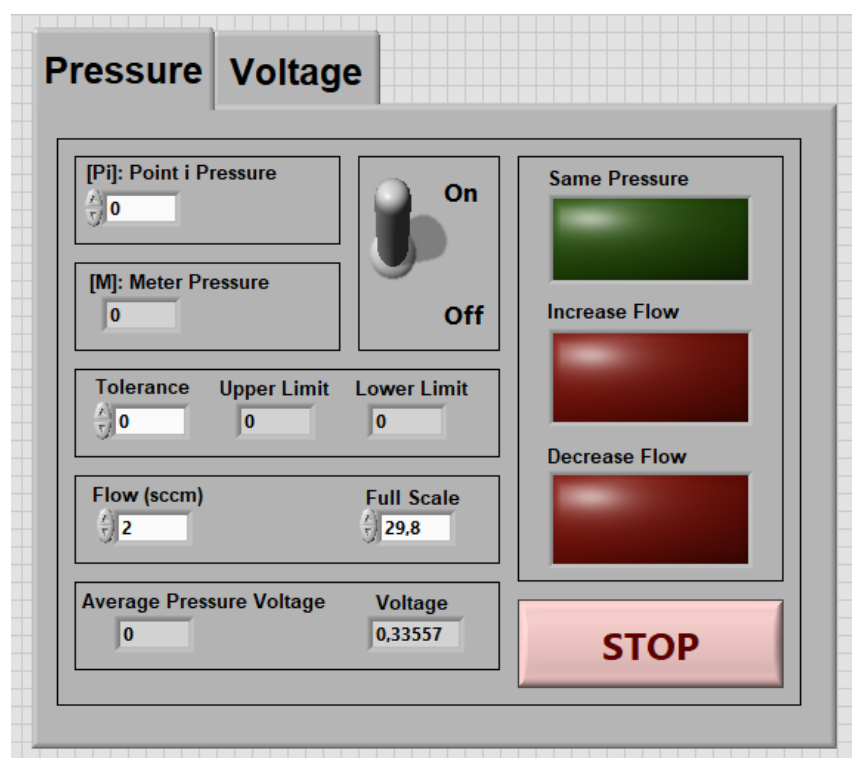

Figure 5: Front panel pressure interface.

From signals, the operator controls flow as indicated until the green light rises, signaling that the pressure has stabilized, continuing to click the Stop button, and opening Voltage tab.

Figure 6 shows pressure reading logic, with readings transformations from 0 to $10 \mathrm{~V}$ for the measured pressure range in Torr according to the tables presented in the Pirani Standard Gauge PVG-550 PVG-552 Operating Manual.5. It also presents the logic behind the pressure tolerance range for determining the limits that control the light emitting diodes (LEDS). 


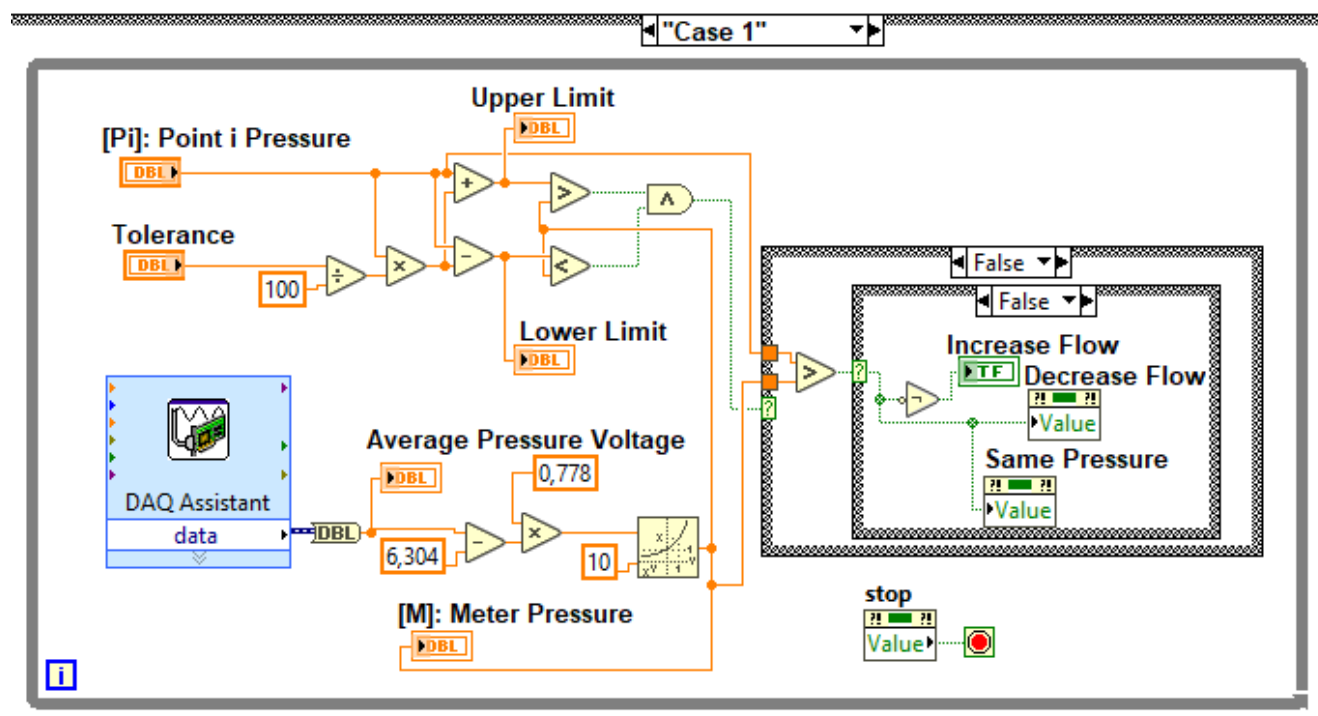

Source: LabVIEW® software.

Figure 6: The logic interface of pressure reading and comparison.

In parallel, but still in the same case structure, the mass flow and gas control, MKS Type 247D Four-Channel Readout, was built, in which it is possible to increase and decrease the flow of gas that feeds the reactor. In Fig. 7 , we see the Boolean that activates the flow and its control.

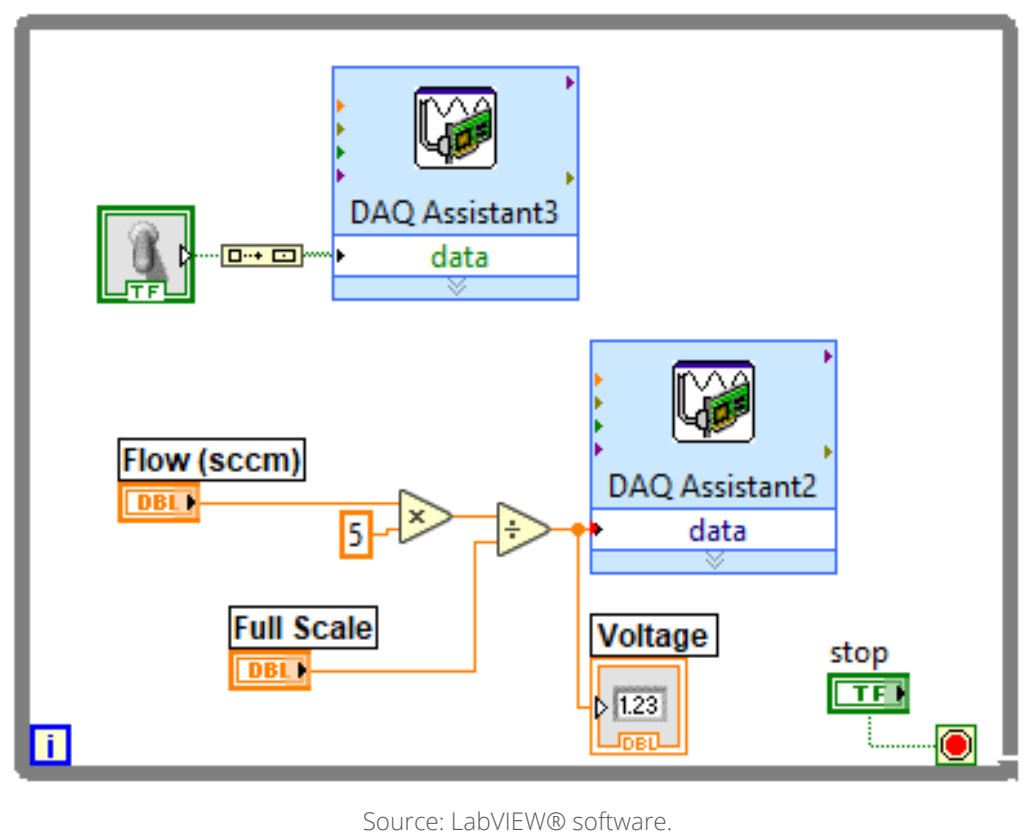

Figure 7: Mass flow control logic interface.

Once the desired pressure is established for the respective point, it is passed to the voltage control and acquisition. For the acquisition of voltage, a commercially available voltage splitter can be used with protection for discharge and electrical arc, which can generate voltage spikes or oscillatory variations.

The voltage splitter used was designed through simulations in the Qucs ${ }^{\circledR}$ software, as shown in Fig. 8, and later built (Fig. 9), to allow reading of 1,000 V transformed into $4 \mathrm{~V}$ without risk of damage to the acquisition board. 


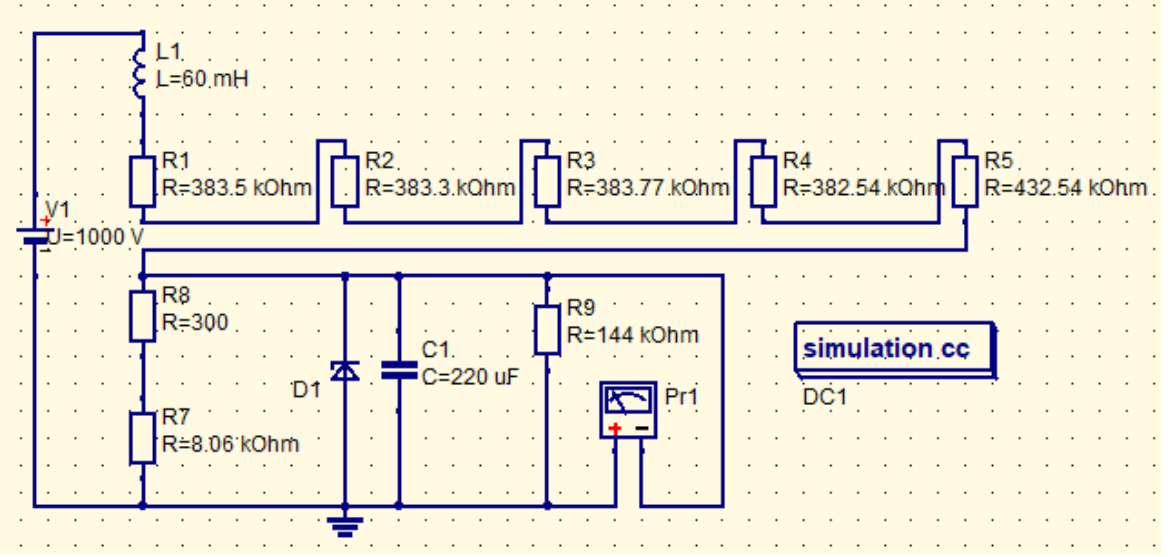

Figure 8: Voltage splitter design.

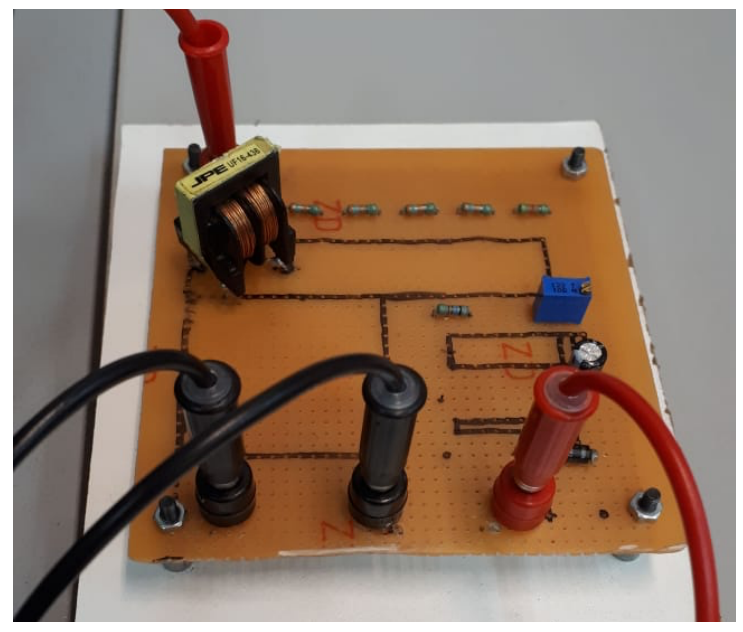

Figure 9: Voltage splitter connected to the acquisition board.

Figure 10 shows the front voltage control panel with the display of reading voltage between electrodes and voltage inserted at the source and the adjustment for the number of peaks to be collected to the arithmetic mean of the voltage value.

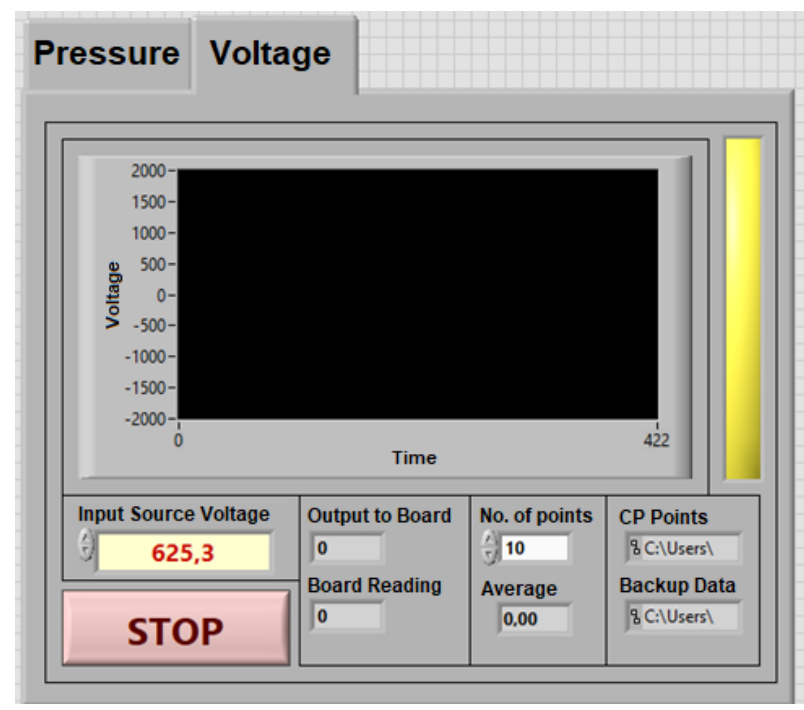

Figure 10: Voltage control front panel. 
The logic interface for reading and voltage control occupies the following case, which is relative to the Voltage window of the front panel, and the numerical coefficients are -250 times for reading from 0 to $4 \mathrm{~V}$, corresponding to reading voltage, from 0 to $1,000 \mathrm{~V}$, and 200 times for source control ranging from 0 to $5 \mathrm{~V}$. In Fig. 11, it is possible to notice the absence of the Boolean that activates the analog control, because it is activated by a button indicated as $\mathrm{S} 2$ on the back of the source.

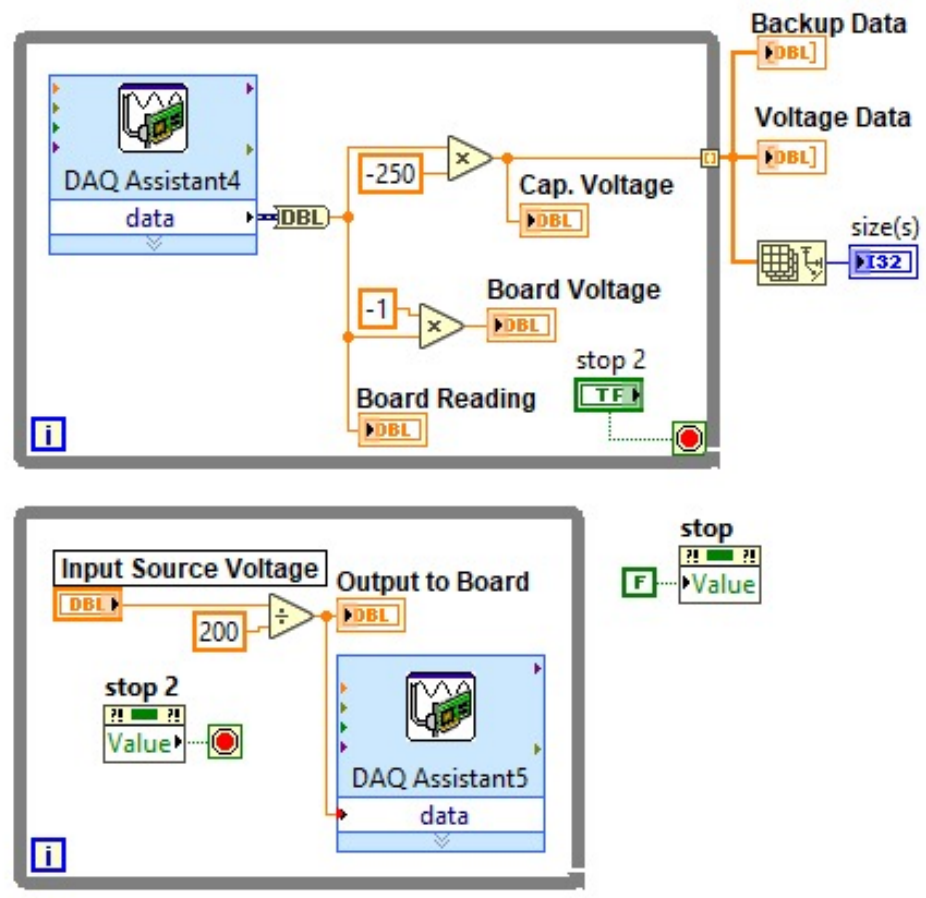

Figure 11: Voltage meter control and source controller logic interface.

The reading of tension is saved together with the pressure order and tension of respective point and, thus, it is repeated for the other points. In the end, we have the list of the points that will compose the Paschen's curve to multiply the distance that is a manual control parameter, but for this work it was kept fixed at $3 \mathrm{~cm}$. The gases studied were atmospheric air and argon, with all parameters fixed, except the pressure and voltage obtained for each point.

\section{RESULTS AND DISCUSSION}

\section{Study of the rupture potential $V_{b}$ as a function of the pressure produced by the distance between the electrodes}

From the values of the rupture voltage $\left(V_{b}\right)$ of the argon atmosphere and the atmospheric air discharge obtained by the LabVIEW ${ }^{\circledR}$ software, the graph presented in Fig. 12 was plotted, providing the values related to the rupture voltage study as a function of the pd product on argon atmosphere and atmospheric air, respectively.

Experimentally, based on the graph of Fig. 12, it was possible to determine the following values for $\mathrm{Vb}_{\min }$ and $\mathrm{pd}_{\min }$ (Table 1).

The ease of breaking an argon gas discharge compared to atmospheric air is related to its stable atomic form. Already the stable form of atmospheric air is molecular, in addition to being a mixture of gases, which causes reduction in the number of electrons by the capture effect and consequent formation of negative ions. The discharge is not self-sustaining for values below $\mathrm{Vb}_{\text {min }}$ and $\mathrm{pd}_{\text {min }}$. Each point on the curve represents an $\mathrm{E} / \mathrm{P}$ value, which is the energy acquired by the electron between two successive collisions. Therefore, $\mathrm{Vb}_{\min } / \mathrm{pd}_{\min }$ represents the minimum energy acquired by the electron along an average free path2,4,6-8. 


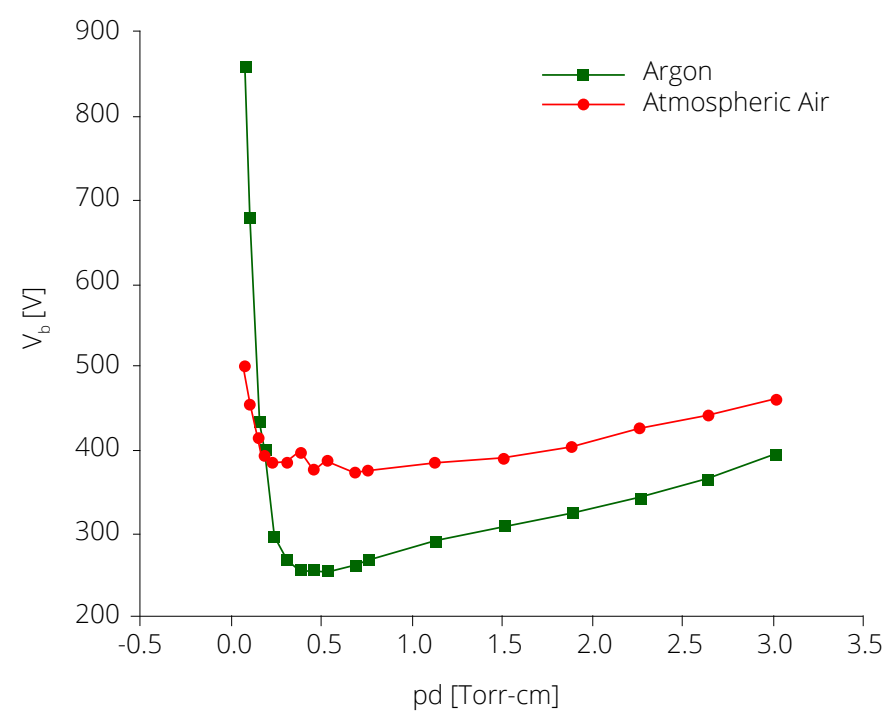

Figure 12: Argon and air rupture voltage as a function of product pressure by distance.

Table 1: Minimum breaking potential and pd product.

\begin{tabular}{ccccc}
\hline \multicolumn{3}{c}{ Atmospheric air } & \multicolumn{2}{c}{ Argon } \\
\hline $\mathrm{Vb}_{\min }[\mathrm{V}]$ & 374 & $\mathrm{Vb}_{\min }[\mathrm{V}]$ & 256 \\
\hline $\mathrm{pd}_{\min }[$ Torr-cm] & 0,682 & $\mathrm{pd}_{\min }[$ Torr-cm] & 0,527 \\
\hline
\end{tabular}

\section{Obtaining constants A and B}

The gas ionization potential can be obtained by the Eq. 19:

$$
V_{i}=\frac{B}{A}
$$

The ionization potential value for atmospheric air (atmospheric air is assumed to have the composition of 20\% oxygen and $80 \%$ nitrogen) and for argon according to Lieberman and Lichtenberg ${ }^{2}$ is $24.33 \mathrm{~V}(\mathrm{~B} / \mathrm{A}=365 / 15=24.33 \mathrm{~V}$ ) and $15.80 \mathrm{~V}$, respectively. The values of the constants $\mathrm{B}, \mathrm{A}$ and $\mathrm{y}$ can be obtained by Eqs. 15, 16 and 17, taking the values presented in Table 1 in Eq. 17 (Table 2).

Table 2: Calculation of the secondary emission coefficient.

\begin{tabular}{cc}
\hline Atmospheric air & Argon \\
\hline $374=e * 24,33 * \ln (1+1 / y)$ & $256=e * 15,80 * \ln (1+1 / y)$ \\
\hline$y=3,51 * 10^{-3}$ & $y=2,59 * 10^{-3}$ \\
\hline
\end{tabular}

The value of A can be calculated using Eq. 16 (Table 3):

Table 3: Calculation of constants A and B.

\begin{tabular}{cc}
\hline Atmospheric air & Argon \\
\hline $0,682=\mathrm{e} / \mathrm{A} \cdot \operatorname{In}\left(1+1 / 2,15 * 10^{-1}\right)$ & $0,527=\mathrm{e} / \mathrm{A} \cdot \ln \left(1+1 / 2,02 * 10^{-1}\right)$ \\
\hline $\mathrm{A}=29,03[\mathrm{~V} / \mathrm{eV}]$ & $\mathrm{A}=30,77[\mathrm{~V} / \mathrm{eV}]$ \\
\hline $\mathrm{B}=706,27[\mathrm{~V} /$ Torr.cm $]$ & $\mathrm{B}=486,19[\mathrm{~V} / \mathrm{Torr} . \mathrm{cm}]$ \\
\hline
\end{tabular}


Using the values of constants A and B for argon, it was possible to obtain the ionization coefficient values per unit length (a) by Eq. 10. The electric field between electrodes, considered uniform for each rupture voltage value, is calculated by the ratio of potential between the electrodes by the distance between them. With the values of $\ln (\mathrm{a} / \mathrm{p}) \times(\mathrm{p} / \mathrm{E})$, the graph of Fig. 13 was created.

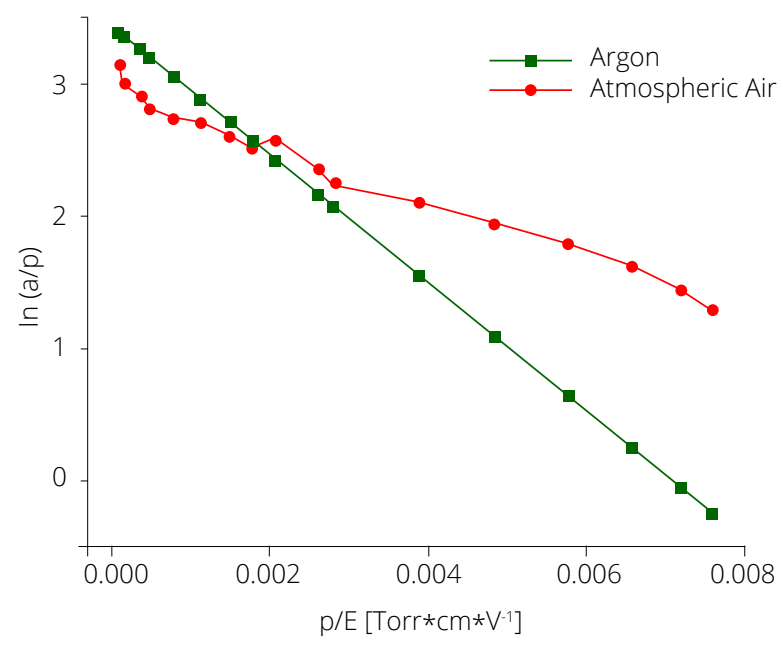

Figure 13: Variation of $\ln (a / p)$ as a function of the ratio between pressure ( $p$ ) and electric field (E).

Applying the Napierian logarithm in Eq. 10, it follows that Eq. 20:

$$
\ln \left(\frac{\alpha}{p}\right)=\ln A-B \frac{p}{E}
$$

It is observed that $\ln (\alpha / p)$ is a linear function of $p / E$, with linear coefficient equals to InA and angular coefficient equals to B. To verify how the secondary emission coefficient ( $y$ ) varies as a function of field ratio pressure (E / $p$ ), the graph in Fig. 14 was plotted.

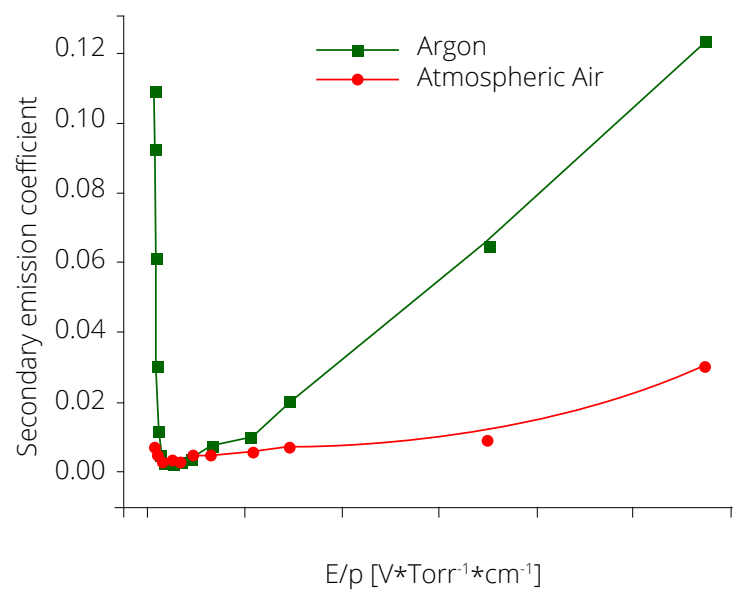

Figure 14: Variation of the secondary electron emission coefficient ( $y$ ) as a function of the ratio between the field (E) and pressure ( $p)$.

For values greater than $800 \mathrm{~V} * \operatorname{Torr}^{-1} \mathrm{~cm}^{-1}$, despite the strange behavior of atmospheric air, the secondary electron emission coefficient was expected to remain virtually constant and close to 0 . By the Townsend's model, the ionization efficiency can be determined, as shown by the Eq. 21: 


$$
\eta=\frac{\alpha}{\mathrm{E}}=\frac{\alpha / p}{E / p}
$$

Which is the number of ionizations per electric field unit. With the values of ionization efficiency ( $\eta$ ) and the field to a pressure ratio (E / p), it is possible to obtain the graph of Fig. 15.

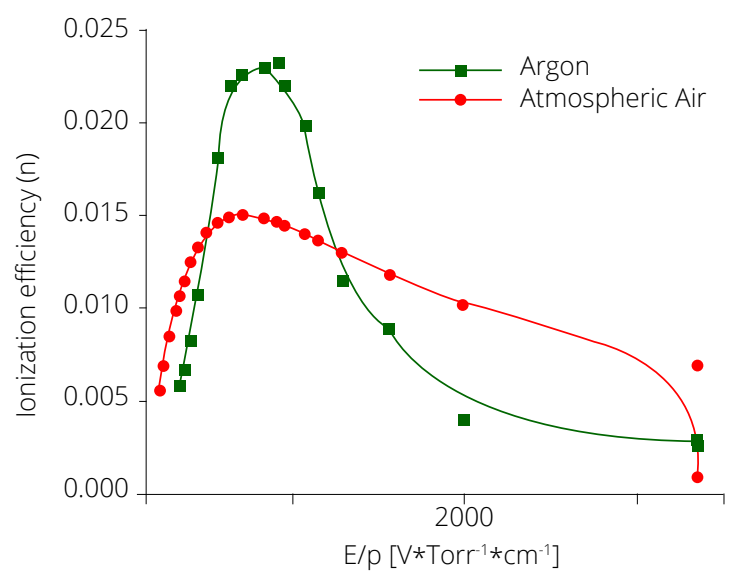

Figure 15: Ionization efficiency $(\eta)$ as a function of the ratio between the electric field (E) and pressure (p).

By Eq. 10, it is possible to calculate the maximum ionization efficiency, namely as Eq. 21:

$$
\eta_{\max }=\frac{A / B}{e}
$$

By analyzing the graph of Fig. 15, it was possible to obtain the values of $B$ and $\eta$ max for both gases and thus obtain again the value corresponding to the constant $A$. The values collected for the constants $A$ and $B$ are presented in Table 4. It is important to notice that A comparison is made with the values obtained using the Paschen's curve and the ionization efficiency graph.

\begin{tabular}{|c|c|c|c|c|}
\hline & \multicolumn{2}{|c|}{ Atmospheric air } & \multicolumn{2}{|c|}{ Argon } \\
\hline & Paschen's curve & $\eta \times E / p$ & Paschen's curve & $\eta \times E / p$ \\
\hline $\mathrm{A}\left(\right.$ Torr $\left.^{-1} \cdot \mathrm{cm}^{-1}\right)$ & 29,03 & 29,03 & 30,77 & 30,77 \\
\hline B $\left(\right.$ V.Torr-1. $\left.\mathrm{cm}^{-1}\right)$ & 706,27 & 706,27 & 486,19 & 486,19 \\
\hline
\end{tabular}

Table 4: Values of constants A and B in atmospheric air atmosphere and argon gas obtained by different methods.

It was possible to plot the rupture voltage $\left(V_{b}\right)$ and the ionization efficiency $(\eta)$ as a function of the pressure product ( $p$ ) by the distance (d) in the same coordinate axis system, for both gases, as shown in Fig. 16.

It can be observed that the values of $\mathrm{Vb}_{\min }$ and $\eta_{\max }$ of Fig. 16 correspond to the same value of $\mathrm{pd}$, which shows that the impact ionization efficiency of electrons is maximum when the breakdown voltage is minimum.

To evaluate the variation of the mean free path $(\lambda)$ for ionizing collisions as a function of the pressure produced by the distance between the electrodes (pd), the graph of Fig. 17 was made.

In the graph of Fig. 17, it can be observed that, by keeping the distance between electrodes fixed and increasing the pressure, the average ionization free path decreases. It is possible to evaluate the variation of the mean free path $(\lambda)$ for ionizing collisions as a function of the electric field to pressure ratio (E / p), as shown in Fig. 18. 

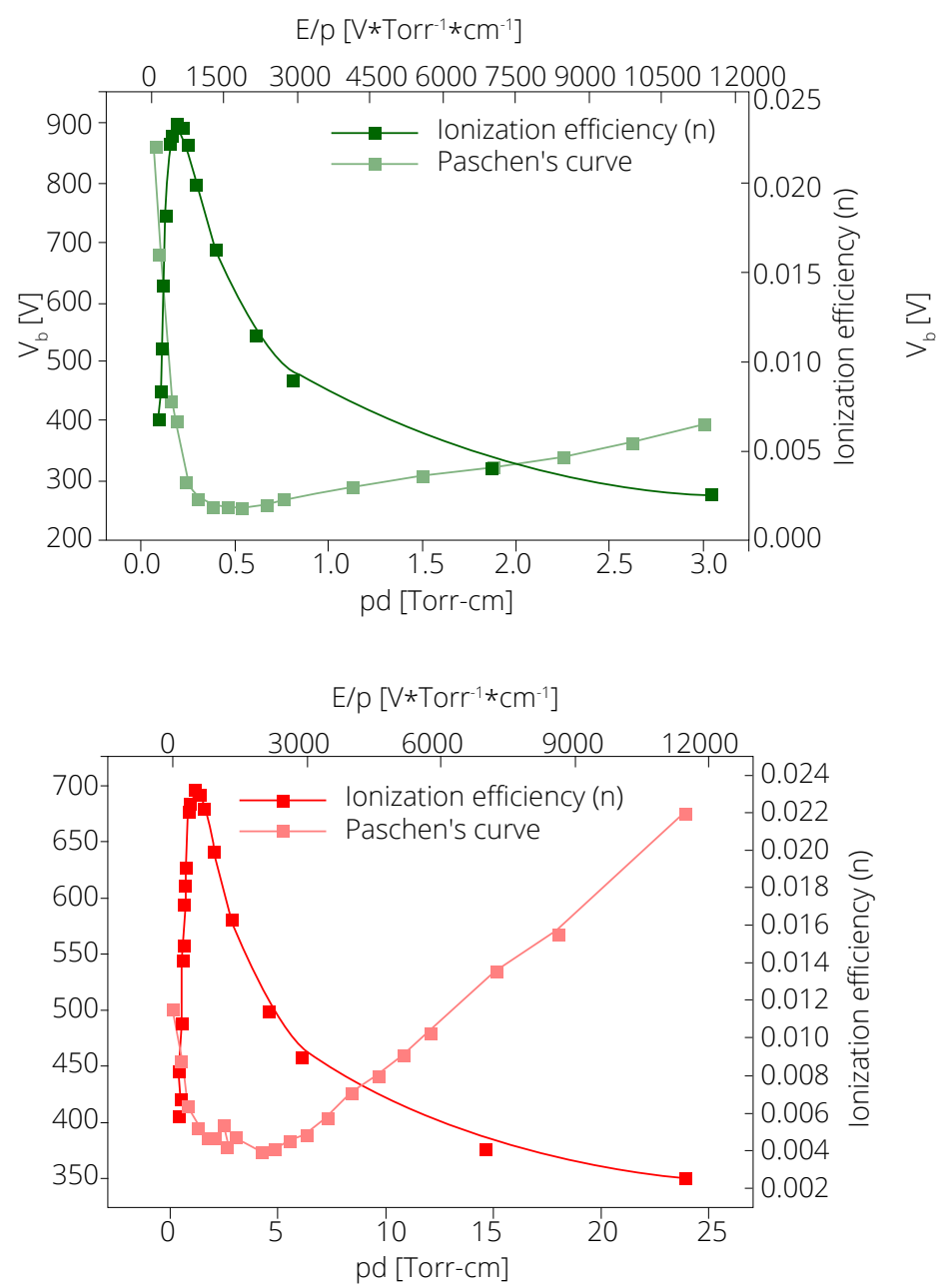

Figure 16: Voltage breakdown and ionization efficiency as a function of pressure product by distance with (a) argon and (b) atmospheric air.

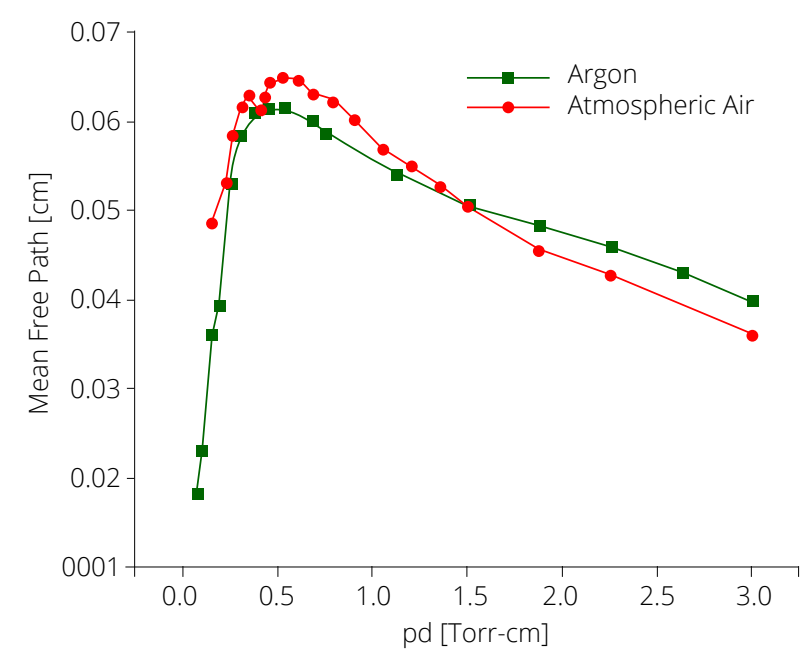

Figure 17: Average mean path for ionizing collisions as a function of pressure produced by the distance between electrodes. 


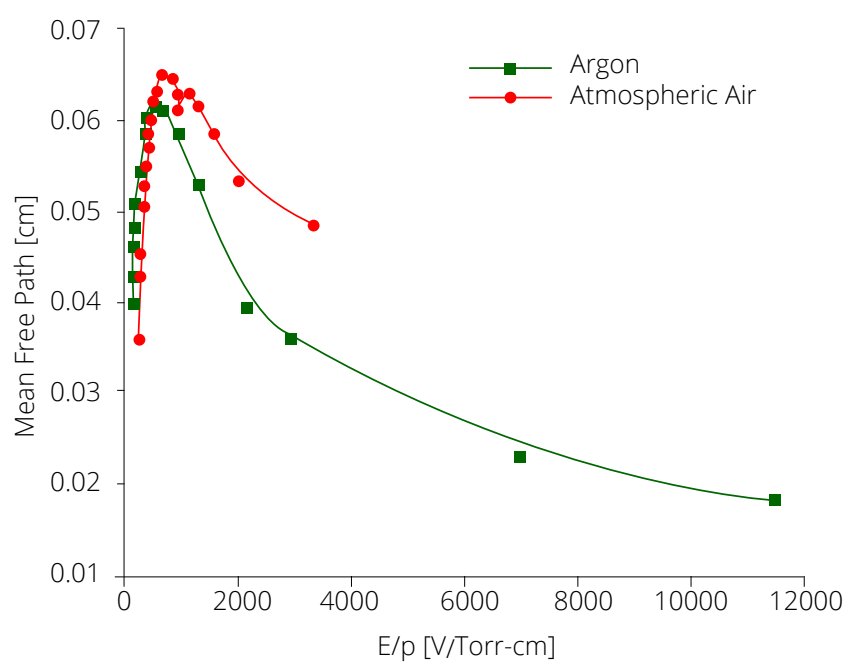

Figure 18: Free mean path $(\lambda)$ for ionizing collisions versus the electric field to a pressure ratio (E / p).

\section{CONCLUSION}

LabVIEW $^{\circledR}$ peripheral device data acquisition and control system is capable of managing and measuring the dielectric rupture parameters of argon and atmospheric gas, using the NI USB 6008 acquisition board, and the limitations encountered have been overcome. It is necessary to adjust their respective parameters for each of the two gases tested, but without impairing the validation of the proposed method.

Through the analysis of Paschen's curves for the configuration with argon gases and atmospheric air, it was observed that the rupture potential for argon gas is lower than for atmospheric air, although the ionization potential of atmospheric air is lower about argon.

The results show that the values of parameters A and B changed according to the gas used in the discharge, i.e., the value of these constants is directly related to the type of gas. The values of A and B obtained from the Paschen's curve and the ionization efficiency graph $(\eta)$ are very close together, and with only two decimal places result in the same value. This behavior occurred for both configurations.

In the graphs of variation of secondary electron emission coefficient ( $y$ ) as a function of the ratio between electric field and pressure ( $E$ / p) for both types of gas, a decrease in secondary electron emission with increase of the electron emission ratio was observed. For this reason, a gradual evolution in the value of $E$ / $p$ for atmospheric air was observed from 500 V.Torr-1 $\mathrm{cm}^{-1}$.

The maximum ionization efficiency is higher when using atmospheric air, but its energy dispersion (E / P) is higher compared to argon gas. Ionization efficiency is related to the first Townsend's coefficient, i.e., the number of electrons generated along the electric field in discharge volume.

Through the analysis of capacitor charge and discharge period, as a function of the chamber pressure, it was seen that, the higher the pressure in the chamber, the faster the capacitor is charged to the point of breaking the discharge, since charge and discharge period decrease.

\section{AUTHORS' CONTRIBUTION}

Conceptualization: Magaldi BV; Pessoa RS and Silva Sobrinho AS, Funding acquisition: Silva Sobrinho AS, Data curation: Magaldi BV; Cesare MP; Ribeiro AA and Martins CA, Formal analysis: Magaldi BV; Cesare MP; Ribeiro AA and Martins CA, Investigation: Magaldi BV and Pessoa RS, Methodology: Magaldi BV; Pessoa RS; Cesare MP; Ribeiro AA; Martins CA and Silva Sobrinho AS, Project administration: Magaldi BV; Pessoa RS; Cesare MP; Ribeiro AA; Martins CA and Silva Sobrinho AS, Software: Magaldi BV; Cesare MP; Ribeiro AA and Martins CA, Validation: Magaldi BV; Pessoa RS and Cesare MP, Visualization: Magaldi BV, Supervision: Pessoa RS; Martins CA and Silva Sobrinho AS, Writing original draft: Magaldi BV, Writing - review \& editing: Pessoa RS; Martins CA and Silva Sobrinho AS. 


\section{FUNDING}

Coordenação de Aperfeiçoamento de Pessoal de Nível Superior

http://doi.org/10.13039/501100002322

Finance Code 001

\section{DATA AVAILABILITY STATEMENT}

All dataset was generated or analyzed in the current study.

\section{REFERENCES}

1. Conrads H, Schmidt M. Plasma generation and plasma sources. Plasma Sources Sci Technol. 2000;9(4):441-54. https://doi.org/10.1088/0963-0252/9/4/301

2. Lieberman MA, Lichtenberg AJ. Principles of plasma discharges and materials processing. 2 ed. New Jersey: Wiley-Interscience; 2005. 757 p.

3. Pessoa RS. Investigações em plasma reativo gerado em descarga de catodo oco plano [thesis]. São José dos Campos: Instituto Tecnológico de Aeronáutica; 2005. 138 p.

4. Abdel-Kader ME, Gaber WH, Ebrahim FA, Al-Halim MAA. Characterization of the electrical breakdown for DC discharge in Ar-He gas mixture. Vacuum. 2019;169:108922. https://doi.org/10.1016/j.vacuum.2019.108922

5. ROWACO. Pirani Standard Gauge: PVG-550 PVG-552. Operating Manual. $2^{a}$ ed. Lexington: ROWACO, 2012 [accessed on Dec 8, 2021]. Available at: https://rowaco.se/app/uploads/2019/03/TQNA79E1-4-Pirani-StandardGauge-PVG-550-PVG-552-Operating-Manual.pdf

6. Manning HLK, Ten Kate IL, Battel SJ, Mahaffy PR. Electric discharge in the Martian atmosphere, Paschen curves and implications for future missions. Adv Space Res. 2010;46(10):1334-40. https://doi.org/10.1016/j. asr.2010.07.006

7. Nehra V, Kumar A, Dwivedi HK. Atmospheric non-thermal plasma sources. Int J Eng. 2008;2(1):53-68.

8. Tendero C, Tixier C, Tristant P, Desmaison J, Leprince P. Atmospheric pressure plasmas: A review. Spectrochim Acta Part B At Spectrosc. 2006;61(1):2-30. https://doi.org/10.1016/j.sab.2005.10.00 